\title{
Seeing by the Starbucks: The Social Context of Mobile Maps and Users' Geographic Knowledges
}

Locating places using maps on mobile devices is an increasingly common practice in modern life. Such maps, including Google Maps and Apple Maps, inform and shape users' geographic understandings. Existing research finds that those who navigate with mobile devices tend to recall landmarks rather than more comprehensive forms of geographic knowledge. However, most of that research gives minimal consideration to social context. Utilizing a qualitative approach and drawing on critical work on vision, maps, and digital data, we explore the contextual, economic circumstances that partially shape the production of users' geographic knowledge through their consumption of mobile device maps. In a focus group experiment, mobile device map users frequently referred to a particular business, a Starbucks location, in a location-finding task. This indicates that social, contextual considerations are important to informing geographic knowledges; the map application providers' business strategies, chiefly advertising, lead to an emphasis on business-type points of interest in mobile maps, which could shape users' subsequent geographic knowledges. This has implications not only for mobile device use, but how technology companies' maps potentially affect everyday understandings of the world around us.

KEYWORDS: wayfinding; navigation; smartphone; geographic vision; critical data studies; Google; mobile device; landmark

I found the Starbucks. That's the library. Does it count if I didn't exactly [find] Andruss Library, but I got Starbucks?

\section{Focus group participant}

Maps on CONSUMER-GRADE mobile devices increasingly mediate how people see, understand, and navigate geography. The Pew Research Center has estimated that 64\% of adults in the United States, and 43\% globally, own smartphones (Poushter 2016). Among US smartphone owners, $90 \%$ use their device to get directions, geographic recommendations, or other location information (Anderson 2016). The popularity of mobile map applications, particularly those with turn-by-turn directions, drives news stories about inattentive travelers being directed hundreds of miles off course, into rivers, or toward a "death-by-GPS" (Milner 2016; Darlington 2015). Such stories feed a moral panic about mobile map users being "sedated by software," inhibiting their ability to interpret geographic information or to navigate without GPS assistance (Royal Institute of Navigation 2015).
New technologies frequently spark moral panics, but recent research on mobile devices and users' geographic knowledge has found that these systems do have drawbacks when compared to paper maps (Ishikawa et al. 2008). Several researchers have found that users tend to conceptualize space only in simple terms, primarily as multiple discrete landmarks (Willis et al. 2009; Münzer, et al. 2006). While these are valuable insights, they lack the contextual considerations that have been highlighted in both cognitive geography and cultural geography debates. Mobile device technologies are neither neutral nor isolated from social influences. Technologies' effects reflect the context of their development, design, and distribution, as well as users' standpoints in practice (Haraway 1991; Feenberg 1999).

Prompted by unexpected research participant responses in a study on cartographic scale, this article explores one important social dimension of mobile map applications that has not been sufficiently examined in research thus far. Specifically, we investigate whether the economic context of mobile map production by companies such as Google 
and Apple might influence the kinds of geographic features that users employ to determine if they have accurately located a place on the map. Incorporating existing research on the social, economic processes that surround the design and use of mobile data and maps, we use qualitative methods to explore the accounts of mobile map users, gaining a richer understanding of how they see the world via mobile maps. We examine how points of interest on the map may come to be used as landmark points of reference by users, apparent in how they think about and communicate geography and location.

Previous geoweb and data science research has found that the features appearing on commercial web maps, such as Google Maps, produce geographies of data both on the map and in practice (Kitchin 2014; Shelton, Zook, and Wiig 2015; Willis 2016). Specifically, these maps are structured around businesses as points of interest. Google, for example, makes money primarily through advertising, so its maps and its algorithms that rank map features are designed to serve that business plan (Zook and Graham 2007a; 2007b; Dalton 2013). Google even recently began placing ads for businesses directly on its maps and using businesses as landmarks in turn-by-turn directions (Dickey 2018; Inhnat 2018).
Users see and understand geography partly in terms of the maps they use (Kitchin 1994; Tversky 1993), and Willis et al. (2009) and Münzer, Zimmer, Schwalm, Baus, and Aslan (2006) make it clear that landmarks are central to users' navigation with mobile devices. In this case, users produce one form of geographic knowledge-landmarks-by seeing cartographic points of interest that are framed and presented to fit the mapmaker's economic imperatives. Thus, this combination of map use and social context may have implications for their understanding of a geography.

As the focus group participant's quote about Starbucks and the library begins to indicate, the underlying social context of mobile map use may affect how users understand the world through mobile technologies. The first half of this article outlines how geographic cognition is contextual and how the production of visual geographic knowledges is socially situated, and from that angle engages the results of existing studies on mobile device use and geographic knowledge production and navigation. The second half employs the results of a study of mobile map users and existing work on the business of web maps to demonstrate the potential role of economic processes in the production of mobile device users' geographic knowledges.

\section{PRODUCING GEOGRAPHIC KNOWLEDGES}

Geographic Knowledges and associated material practices have been studied and theorized by many geographers and allied scholars. While this realm includes a wide variety of theories and methods, foundational work in both cognitive geography studies and cultural theory points to the importance of contextual constructions of geographic knowledges in practice, regardless of the underlying neurological structures or networks involved (Montello and Freundschuh 2005). While most research indicates that device use facilitates impoverished or simplified spatial knowledges, it has rarely incorporated these contextual considerations, particularly economic ones, such as the business imperatives and designs of the phoneand mapmakers.

\section{COGNITIVE GEOGRAPHIES AND MAPS}

Cognitive research on geographic knowledges offers a variety of frameworks, ranging from the construction of knowledge through learning, to connected neural networks, to linguistically influenced situated cognition, to evolutionary development. Most spatial cognition frameworks involve both underlying neural structures, with individual variations, and culturally situated learning as we orient ourselves and navigate every day (Montello and Freundschuh 2005). Regardless of the neurological structures involved, how geographic features are ontologically recognized, categorized, communicated, and used varies between cultures (Montello 2009). Within, or at times, despite, those cultural variations, most cognitive research on geographic knowledges tends to be structured around of three kinds of geographic features: landmarks, routes composed of a series of landmarks in order, and survey or configurational knowledge of interconnected landmarks and routes across scales (Montello and Freundschuh 2005).

Within the range of cognitive research on geographic knowledges, researchers advance cognitive maps as a framework for conceptualizing landmarks, routes and 
surveys features in concert. Again, researchers highlight the contextual, constructed nature of cognitive maps, noting how they change and are partly based on subjective knowledge. "[C]ognitive maps are not independent of time and space" (Kitchin 1994, 3) "since each environment exists in a time-space context, so too will cognition of those environments" (Moore and Golledge 1976, 11). Using linguistic constructions, Tversky (1993) illustrates the limitations of cognitive maps and calls for more flexible frameworks that could include recollections of journeys and verbal directions, memories of maps, geographic facts, and even linguistic families. Such frameworks could certainly include memorable corporate branding, and Kitchen (1994) even posits advertising as a potential application for cognitive map research.

Cognitive geography approaches are also used in cartography and GIScience to improve map design. This work focuses on schemata, "mental structures that the map users employ to mediate between what s/he already knows and what s/he sees in a map. In other words, they are the means by which the map users construct information from visual representations like maps" (Griffin 2017, 50). Better understanding a schema, for example a learned categorization of types of surfaces on which "we walk, lay, and sit," can help inform how map data should be symbolized and included in a map or GIS (Freundschuh and Egenhofer 1997, 363). Thus, schemata draw on both a map-reader's direct experience as well as culturally shaped, learned conventions, such as water being commonly symbolized with blue (MacEachren 1995). Cognitive geography research indicates that geographic knowledges are at least partly contextual and constructed, particularly in practice and when involving maps and geographic communication technologies.

\section{SOCIAL VISIONS}

Using a cultural approach to a similar topic, Haraway (1991) warns of the limitations of disembodied, technologically mediated visual knowledge, for it obfuscates how technologies and associated knowledges are inherently shaped by social circumstances and power relationships. Embodied, situated knowledges constitute a productive alternative approach, open to multiple ways of knowing and thus more possibilities for better understanding the world. For researchers, this means being open to and taking seriously the accounts and technologically inflected standpoints of subjects to better understand their perspectives and what their knowledges make possible. "Situated knowledges require that the object of knowledge be pictured as an actor or agent, not a screen or a ground or a resource..." (Haraway 1991, 198).

In geographic cases, viewing subjects are co-produced with visual geographic knowledges through embodied viewing practices driven and shaped by broad social processes (Cosgrove 1998; Rose 2003; 2007). Today, mobile devices are powerful tools for producing visual geographic subjects and knowledges, for they can travel with a user and act as a resource on-site. For example, Wilson (2011) describes the use of mobile devices as city residents conducted a visual neighborhood assessment survey in Seattle. Through their social context and the structure of a mobile application, users became trained to see some things, such as signs of urban decay, and not others. In this way, the governmental terms of the survey, mediated by the mobile device, facilitated the production of neoliberal viewing subjects and their knowledges (Wilson 2011).

The emphasis on the production of situated knowledges through practice is also apparent in recent work on maps. Critical cartography articulates how maps are always produced within social contexts, part of powerful cultural projects such as state-building, consolidating private property, or profit-seeking by businesses (Crampton 2010; Schulten 2012; Sutton 2015). These political contexts inherently involve multiple subject positions and political economies of geographic technologies (Stephens 2013; Alvarez León and Gleason 2017; Thatcher, O’Sullivan, and Mahmoudi 2016; Dalton 2018). Economic considerations are vital to the development of new technological innovations and use practices. For example, according to mobile technology expert Brian Profitt, geographic data from mobile device use is a "hot commodity," based in large part on the perceived value of targeted advertising (quoted in McBride and Oreskovic 2013). Choices made about which data are or aren't incorporated into a mapping service for business or functional reasons delimits how that service can best and most easily be used (Haklay 2013). Moreover, it is through use that a map's purpose and economic value is realized by helping to produce a viewing subject's knowledges and spatial actions. Thus, maps are not just political and culturally situated, but facilitate the recursive production of knowledges through practice (Pickles 2004; Dodge and Kitchin 2007). In the case of mobile devices, mapping technologies facilitate location-aware services and conspicuous displays of users' 
geographic behaviors that provide revenue for the company providing the service (Wilson 2012; Pink and Hjorth 2012). Only a few recent qualitative studies engage the contextual nature of geographic knowledges and navigation or place-finding, highlighting the importance of everyday cartographic practices to underlying social processes (Brown and Laurier 2005; Wilmott 2016).

\section{GEOGRAPHIC KNOWLEDGE AS ACQUIRED WITH MOBILE DEVICES}

In contrast to these contextual studies, a growing number of researchers are attempting to assess the impact of consumer-grade geographic mobile technologies on geographic knowledge acquisition. Tests measure research participants' directional error, travel time, time stopped between moves, subsequent memory of places and landmarks, and the accuracy of their survey knowledge on sketch maps. Most of the studies that compare mobile device navigation with navigation supported by other methods, such as paper maps, indicate some kind of lesser performance by mobile users. Ishikawa et al. (2008) found that research participants using a GPS-enabled mobile map on a phone travelled slower, made larger directional errors, drew sketch maps with poorer topological accuracy, and finally, rated navigation as harder, than those using a traditional paper map. Other studies have found similar results (Münzer, Zimmer, and Baus 2012; Waters and Winter 2011), including with augmented reality hardware (Huang, Schmidt, and Gartner 2012).

Two factors may explain the disappointing results of mobile device maps within the frame of successful geographic knowledge acquisition. First, some mobile device studies were performed while mobile maps were quite new (Münzer et al. 2006; Ishikawa et al. 2008). The maps and user interfaces lacked touchscreens and were neither intuitive nor easy to work. Furthermore, research participants may not have had experience with using maps on such devices. In fact, a later study showed some improvement in participants' travel speed and time spent stopped, possibly owing to users' increased familiarity with mobile maps (Field, O'Brien, and Beale 2011). Users' professed confidence in navigating with mobile devices (Wang, Park, and Fesenmaier 2012; Ricker, Schuurman, and Kessler 2015) may indicate that user-interaction designs are improving.
A second factor has less to do with the specific design of mobile maps than the form of attention that they require of the user versus a paper map. Wayfinding research has long illustrated that passive navigation practices make for poor geographic knowledge acquisition, facilitating simplified forms of geographic knowledge that are often focused on landmarks rather than a mixture of landmarks and other more complex features and connections (Held and Hein 1963; Parush, Ahuvia-Pick, and Erev 2007; Willis et al. 2009). In this way, mobile maps discourage users from thinking and learning about the area around them. As Willis, Hoelscher, Wilbertz, and Li argue: "A mobile map with automated position information (i.e., self-localization) essentially enables and possibly even encourages someone using it to stop active engagement and to become the passive receiver of information...” $(2009,108)$. Within that passive practice, what geographic knowledge mobile device users do retain tends to be based on landmarks. For example, in Münzer, Zimmer, Schwalm, Baus, and Aslan's (2006) study, research participants were asked to navigate between two points in an unfamiliar zoo using a paper map or a mobile device. Researchers tested participants' acquisition of spatial knowledge in terms of route knowledge, defined as a series of visual landmarks and impressions from a person's egocentric perspective, and/ or as survey knowledge of the zoo's layout, a "map-like representation from an allocentric perspective" (Münzer et al. 2006, 301). After navigating the zoo, mobile device users scored markedly better at landmark-based route knowledge than survey knowledge, while paper map users scored substantially better than device users in both categories. Willis, Hoelscher, Wilbertz, and Li describe similar findings, concluding that "mobile map users acquire a more fragmented and regionalized knowledge representation based on strong connections between locally clustered landmarks along the route" $(2009,100)$. This tendency may be exacerbated by the ways that map readers tend to ignore task-relevant information in what they perceive on maps unless it is visually salient (Fabrikant, Hespanha, and Hegarty 2010). Mobile map use does not encourage users to develop complex schematic or configurational networked understandings of an area. Instead, landmarks are vitally important to mobile map users, even in device-assisted passive use.

Within wayfinding scholarship, landmarks are traditionally understood as external objects that are "easily identifiable" as a "point reference" (Lynch 1960, 78). Thus, an 
important question for wayfinding research is: what makes a geographic feature relevant and prominent enough to serve as a landmark? To answer that question, researchers have attempted to develop a comprehensive theory of what makes a feature sufficiently "salient" to be a landmark. Sorrows and Hirtle (1999) and Raubal and Winter (2002) propose a combination of visual novelty, cognitive meaning or cultural and historical importance, and spatio-structural centrality or connectedness. However, these proposals give relatively little attention to how or why a landmark accrues or loses cultural meaning, and therein salience, over time through its social and economic context. For example, Raubal and Winter categorized cultural and historical importance by scoring standardized formal qualities of aesthetic novelty. Others forgo such considerations entirely by focusing on wayfinding and geographic knowledge acquisition in decontextualized, purpose-built virtual environments (Bartie et al. 2015; Basiri et al. 2016; Hamburger and Roeser 2014). These approaches presume a static, always already existing form of landmark salience. Without accounting for the cultural production of landmarks and how their meaning changes over time, it runs the risk of overlooking landmarks that social and economic processes make meaningful, but that appear banal.

\section{GEOGRAPHIC KNOWLEDGE PRODUCTION IN A SOCIAL, TECHNO- LOGICAL CONTEXT}

As Montello and Freundschuh (2005), Kitchin (1994), Brown and Laurier (2005), and Wilmott (2016) demonstrate, research on maps and their use can take many forms. Both cultural and cognitive geography research show the many potential forms of situated or contextually dependent, constructed geographic knowledges. However, most research thus far on how people use geographic services on mobile devices uses the conceptually limited framework of spatial knowledge acquisition: a universal, external set of generic geographic characteristics or features waiting to be imperfectly acquired and applied by research subjects. While findings on the limitations of navigating with the assistance of mobile devices and the importance of landmarks for wayfinding and navigation are valuable, these analyses categorically set aside many contextual considerations, overlooking how situated processes shape geographic knowledges. They do not consider who made the mobile map and why, and few consider what research subjects think of using the map.

Studies that focus on users' accounts offer additional considerations. When asked, mobile device users report increased confidence when navigating, meaning they may be more navigationally adventurous, at least in the right context (Wang, Park, and Fesenmaier 2012; Ricker, Shuurman, and Kessler 2015). ${ }^{1}$ Using qualitative approaches, Speake (2014) and Axon, Speake, and Crawford (2012) demonstrate a strong preference among young people for mobile maps over paper maps and multiple accounts of feeling reassured by smartphone navigation and anxiety at the prospect of losing it. Their participants also saw the financial cost of devices as a significant downside to digital navigational tools.

Speake (2014) and Axon, Speake, and Crawford's (2012) findings about costs are singular in that they reference economic circumstances. The uneven nature of economic costs and related user concerns, as well as the business imperatives of the companies that offer mobile maps and smartphones, are factored out of assessments of landmark salience and spatial knowledge acquisition with mobile devices. Yet contextual social influences, such as the design and branding of mobile devices and maps, are significant in shaping users' feelings towards and practices with them. Approaching geographic knowledges as produced by subjects situated within social processes allows for consideration of these socially contingent factors. The subjects who produce their geographic knowledges with mobile maps do so from multiple situated, embodied standpoints across a broad, uneven constellation of races, ethnicities, classes, languages, and gender identities (Wilmott 2016; Graham 2015; Taylor 2015; Stephens 2013).

One shared aspect across these contexts is the role of the mobile map service provider. Technologies are designed to fulfill social purposes, not just for the end-user, but also the company offering the hardware or service. Users have some flexibility in what they do with a technology, or a 
map, but their actions are delimited by the built-in material structure created by the designer (Feenberg 1999; Thatcher 2017). Developers at Google and Apple design consumer-grade mobile map services and the map algorithms that prioritize which geographic features to symbolize (Graham 2005; Zook and Graham 2007a). Market forces drive the current development of geospatial technologies and media, including mobile maps (Dalton 2015; Thatcher, O'Sullivan, and Mahmoudi 2016; Alvarez León and Gleason 2017). As a result, there are stark differences around the globe and within many countries in the service provision of mobile maps and the extent of geographic data available (Taylor 2015; Graham 2015). Access to data describing an area is not guaranteed to produce a social good; navigational technologies can use data about an area in ways that are not positive for its inhabitants. For example, a technology patented by Microsoft attempted to utilize local data to route travelers around undesirable neighborhoods, reinforcing such areas' "ghettoized" status (Thatcher 2013).

The political economy of geographic data is an inescapable part of current mobile maps and associated user practices. The ultimate purpose of Google Maps is to advance Google's business strategy: providing a free-to-use service that fosters more and more web (and map) usage flowing through Google's servers, which in turn provides more user data that facilitates targeted advertising (Battelle 2005; Gundotra 2008; Hillis, Petit, and Jarrett 2012). Businesses are ideal points of interest to include on mobile maps because they are typically associated with a discrete street address, generally need to advertise (Dalton 2013), and users often wish to locate them. Finally, map services are a rich resource of location data, which is very valuable for targeting subsequent ads (Swift 2011). Consequently, Google offers maps that are materially designed to facilitate advertising, with geographic features that are practical and that also suit that focus. Zook and Graham (2007a; 2007b) have illustrated how companies shape the algorithmic selection of features on digital maps, particularly in search results. At an extreme, reliance upon this type of search-based navigation has been proposed as a type of "teleological navigation," wherein users only move through - and therefore come to know-environments in terms of end-point considerations for a particular trip (Sutko and de Souza e Silva 2011, 816).

Given the complex interplay between map designer, mobile interface, and the map user, understanding the role of economic processes in geographic knowledges that involve mobile devices requires us to consider the social contexts in which these maps are designed and used. As the scholarship on these technologies makes clear, these devices, services, and maps are designed by private companies to advance their business plan. Thus we cannot consider mobile map use in isolation from consumption. Businesses frequently show up on the map even when they are not the focus of the search. In the following sections, we analyze how users employed mobile maps to identify a location on the map in focus groups, revealing a strong reliance on a business point of interest-a particular Starbucks location-on the map. That branded point of interest serves as a landmark point of reference, perhaps because it is far more prominent on the map than it is on ground.

\section{RESEARCH QUESTION AND METHODS}

The POPUlARITY OF mobile maps means it is important to consider how they impact their users' understandings of the geography around them. Research to date identifies serious drawbacks and complications to their use in terms of geographic knowledge acquisition, so it is important to focus on additional considerations: are technologically mediated social and economic processes also shaping users' production of geographic knowledges as they attempt to understand and communicate about geography, and in particular about landmarks?

To begin to answer this question, principal investigator Craig Dalton and a research assistant, Karen Wilwol, utilized a series of focus groups. The primary and original research aim of the focus groups involved users' conceptions of cartographic scale; the themes engaged here only emerged as we began to evaluate the data. Focus groups are used in both cartographic design/usability (Monmonier and Gluck 1994) and wayfinding (Axon, Speake, and Crawford 2012) research to explore and engage users' attitudes, understandings, and behaviors in larger numbers than individual interviews allow. The method allows direct questions (with follow-ups) that can be qualitative and open-ended, focusing on how and why. Furthermore, participants are not "on the spot" for the entire session, reducing pressure and possible intimidation 
and allowing researchers to observe how participants use maps on their phones and interact with each other when doing so. When conducting focus groups, it is vital to make sure that no single participant, or subset of participants-especially men-dominates the conversation. In this case, we took special care to make sure everyone had the opportunity to participate, repeating questions and sometimes posing them directly to each participant to ensure that all could respond if they chose (though it was not required). The focus groups themselves were video-recorded in a conference room and each lasted approximately one hour. Research participants were recruited from general education courses in the Department of Environmental, Geographical, and Geological Sciences at Bloomsburg University of Pennsylvania. They were required to own and bring a mobile device with at least one mobile map application. A total of 62 students participated, a number that is comparable to similar research studies (Axon, Speake, and Crawford 2012, $\mathrm{n}=46$; Willis et al. 2009, $\mathrm{n}=24$; Ishikawa et al. 2008, n=66; Münzer et al. 2006 $\mathrm{n}=64)$. Of the participants, 43 were women and 19 were men, and all were undergraduate college students in their late teens and early twenties. Each was given a $\$ 10$ bookstore gift card for their participation. The thirteen focus groups ranged in size from three to six participants.

Most studies of the geographic use of mobile devices utilize a standardized device and map in an unfamiliar area to assess how participants learn and retain geographic knowledges using different media or design variables. In contrast, participants in our study used their own phone and a mobile map of their choice, to better reflect their actual everyday behavior. Most participants (81\%) used iPhones and nearly all the rest had Android phones. All participants stated that they used either the Google Maps or Apple Maps applications, though we observed some participants mistaking the default (Apple) Maps application on their iPhone for Google Maps.
Each focus group involved general questions about participants' geographic use of mobile devices, two scale-related cartographic tasks accomplished with their phone, and questions about their actions with the phones and the results of the tasks. In the task relevant to the research we report here, we asked participants to locate the Bloomsburg University library in their preferred mobile map on their own smartphone. We observed their actions and how they engaged each other, and asked questions such as "How did you go about trying to locate the library?" and "If you located it, what makes you think you found the right place?" Focus group participants frequently talked in unprompted ways to one another about their phones, the map, and previous experiences as they performed the task, as they would in actual everyday practice. These conversations were recorded and included in the transcript of each focus group. Most Bloomsburg students already have a well-informed understanding of the campus and know where the library is located. The purpose was to better understand how they used their local experience to approach mobile maps on their own in an easy, low-pressure environment before proceeding to a more complex, scale-oriented task focused on preparing to navigate to an unfamiliar location.

Once we completed the focus groups, we transcribed them and coded the responses by task and topical theme. Given Münzer, Zimmer, Schwalm, Baus, and Aslan (2006) and Willis, Hoelscher, Wilbertz, and Li's (2009) findings, we also coded responses in terms of mentions and discussions of landmarks, sub-coded by which landmark, mentions of routes, and expressions of survey knowledge such as recognizing campus by the shape of the road network. Coding categories were not mutually exclusive. We also qualitatively engaged common themes expressed in the participants' accounts to understand their perspectives and what led them to say and do what they did.

\section{RESULTS}

DesPite THEIR FAMILIARITY with campus, the vast majority of participants used a search function to find the library, either within the mobile map application or by searching the web and then copying and pasting the name and/or address into the mobile map. A few started with their phone's GPS-derived current location and panned and zoomed over to the library.
When we asked participants what made them think that they had located the library correctly, 48 of the 62 (74\%), including at least one person in each of the 13 focus groups, referred to landmarks of some kind, most often buildings or parts of buildings, some of which were auto-labeled. Thirty-five (56\%), including at least one person in every focus group, provided information that indicated 
they possessed survey knowledge of the area, such as the organization of campus, or the structure of nearby streets. Thirty (48\%) mentioned both landmarks and spatial configuration, including $86 \%$ of those who mentioned the spatial configuration. These results are somewhat consistent with Willis et al.'s (2009) conclusions that mobile device users have a tendency to understand space in terms of landmarks. While research participants were already familiar with the area (unlike in many similar studies), almost half did not mention spatial configurational knowledge. The most commonly referenced landmark was, unsurprisingly, the library, which was named in the task directions and questions.

Interestingly, the underlying social context of mobile mapping is apparent in the other landmarks participants referred to. By far the most commonly identified landmark, other than the library, was Starbucks, which has a

\begin{tabular}{|c|c|c|}
\hline $\begin{array}{c}\text { At least one landmark (including } \\
\text { the library) }\end{array}$ & $\begin{array}{c}\text { Number } \\
\text { (out of 62) }\end{array}$ & $\begin{array}{c}\text { Percent } \\
\text { of total }\end{array}$ \\
\hline $\begin{array}{c}\text { Spatial configuration } \\
\text { Both }\end{array}$ & 38 & $57 \%$ \\
\hline $\begin{array}{c}\text { At least one mention of } \\
\text { Starbucks }\end{array}$ & 30 & $48 \%$ \\
\hline $\begin{array}{c}\text { At least one mention of a } \\
\text { landmark other than Starbucks } \\
\text { or the library }\end{array}$ & 15 & $24 \%$ \\
\hline
\end{tabular}

Table 1. Study participants' mentions of landmarks and spatial configuartions.

\begin{tabular}{|c|c|c|c|c|}
\hline Focus group & $\begin{array}{l}\text { Number of } \\
\text { participants }\end{array}$ & $\begin{array}{l}\text { At least one mention of a } \\
\text { landmark (including the library) }\end{array}$ & $\begin{array}{l}\text { At least one mention of } \\
\text { Starbucks }\end{array}$ & $\begin{array}{l}\text { At least one mention of } \\
\text { a landmark other than } \\
\text { Starbucks or the library }\end{array}$ \\
\hline 1 & 5 & 4 & 0 & 1 \\
\hline 2 & 4 & 2 & 0 & 0 \\
\hline 3 & 5 & 2 & 0 & 1 \\
\hline 4 & 4 & 3 & 1 & 0 \\
\hline 5 & 6 & 3 & 3 & 2 \\
\hline 6 & 5 & 3 & 1 & 1 \\
\hline 7 & 6 & 6 & 2 & 1 \\
\hline 8 & 3 & 2 & 0 & 1 \\
\hline 9 & 3 & 3 & 2 & 2 \\
\hline 10 & 6 & 6 & 1 & 1 \\
\hline 11 & 6 & 6 & 3 & 2 \\
\hline 12 & 5 & 5 & 1 & 0 \\
\hline 13 & 4 & 3 & 1 & 1 \\
\hline Total & 62 & 48 & 15 & 13 \\
\hline
\end{tabular}

Table 2. Number of participants who mentioned landmarks. 
franchise in a corner of the university library amidst multiple other notable features. Fifteen (24\%) of the participants, in 9 of the 13 focus groups, referred to Starbucks, more than all the references to other landmarks on campus together other than the library itself. Other mentioned landmarks included other buildings and parking lots, though none were referred to frequently.

Qualitative analysis of research participants' accounts show that Starbucks-as-landmark served several roles. Participants referenced it most often as confirmation of the library's location when researchers asked what made participants think they had the right place:

Even though it doesn't say [library], but I see the Starbucks symbol for it being inside of the library, so that's how I know that's where the library would be.

I just scrolled over to see where it was from my location. The actual-on the Maps app, it doesn't say where the library is, it just says where Starbucks is, so from Starbucks.

Instead of using it as confirmation, one participant entered "Starbucks" directly as the search query.

I searched for Starbucks because I knew that would probably come up faster than the specific library.

In several cases, Starbucks was such a strong point of reference that participants misidentified the library's location because they located the other Starbucks franchise on campus and assumed it was the library. That second Starbucks is on the other end of campus, near where Apple's Maps app pinpoints the university's campus-wide street address.

At least two participants, possibly more, caught that error.

Well now I'm confused because I thought it was bringing me to the [library]. I had the Starbucks icon pop up as well, and I thought it was the Starbucks in the library, but then I saw the hospital now, so it's totally not.

The pin is on the Starbucks that I think may be in the Commons? Because I know that the

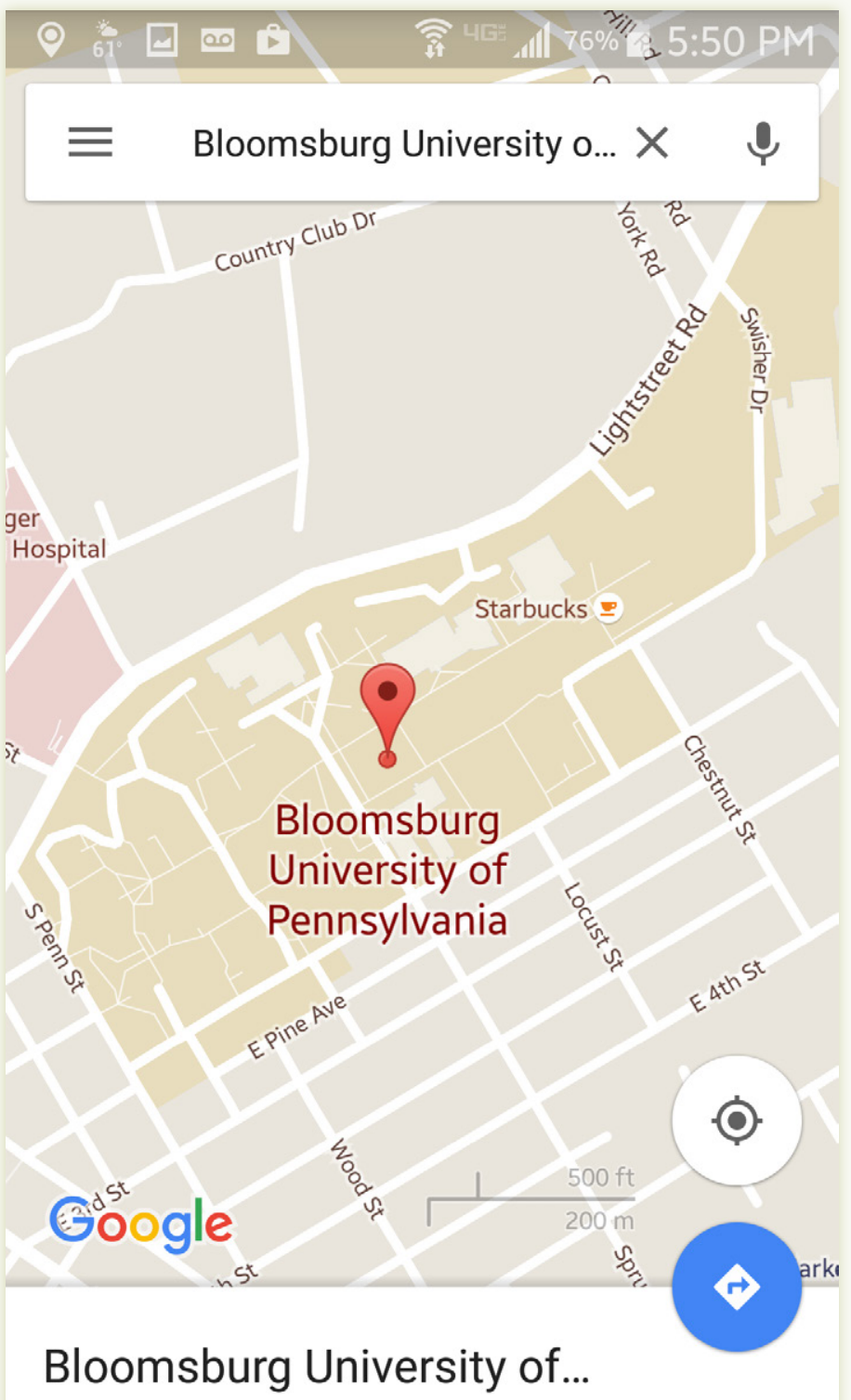

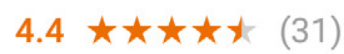

Route

Figure 1. Starbucks-as-landmark in the Google Maps mobile app.

library is more up here. (indicates where by pointing to phone). Not down here... I know that the Bloomsburg Hospital is on lower campus, lower on the campus, and the library is up more.

Researchers also observed two other participants who didn't catch the error, and there may have been more; exact numbers are difficult to determine because participants may not have admitted or even known they had the wrong location, at least initially. While there did not appear to be many cases of misidentified Starbucks locations, it is noteworthy that such a problem is even possible and 


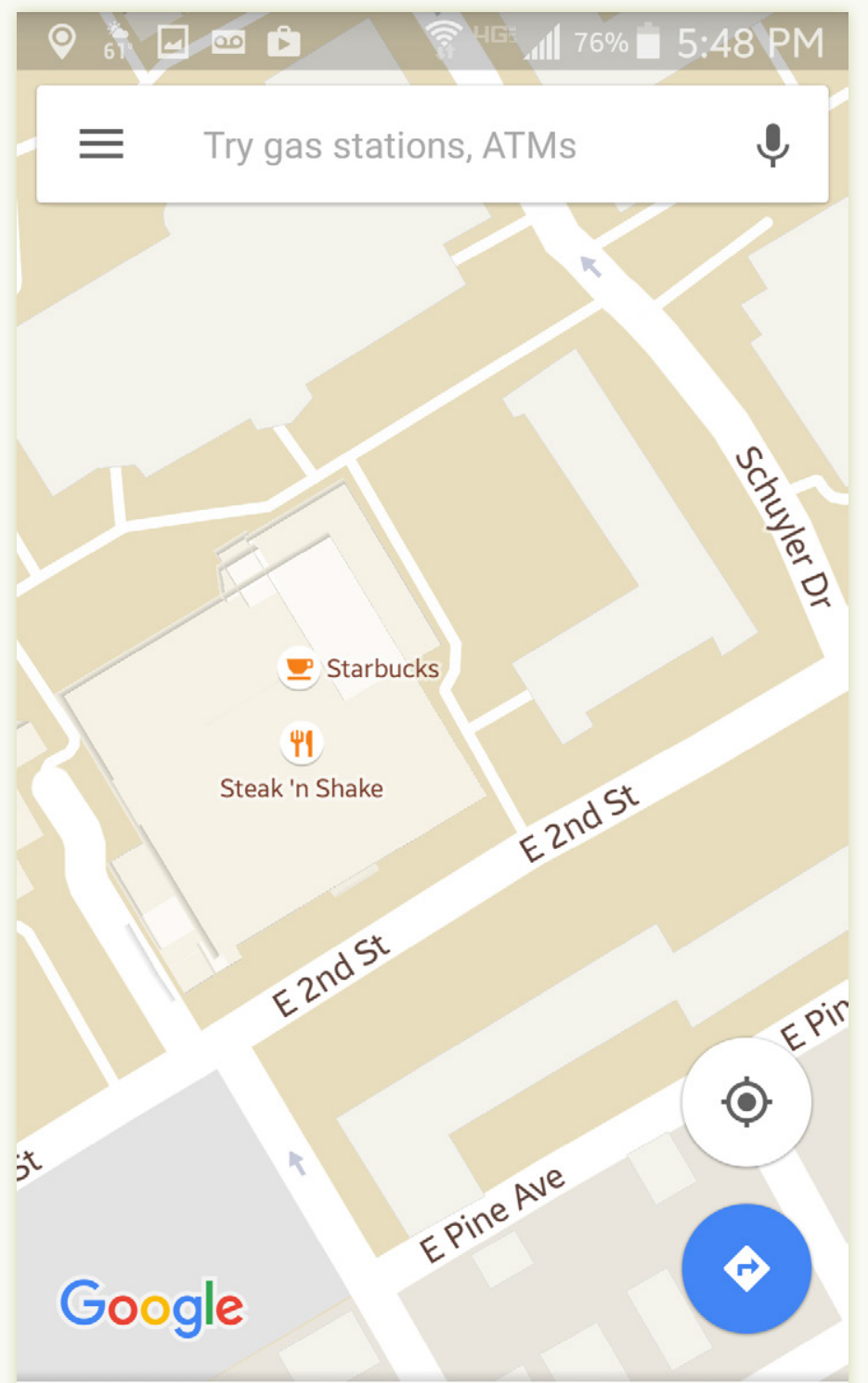

\section{Explore food \& drinks near Elwell Hall}

Figure 2. The other Starbucks on Bloomsburg University's campus in the Google Maps mobile app.

was common enough to appear repeatedly across multiple focus groups in a study of this size.

\section{STARBUCKS' SALIENCE}

Of all the non-library features on Bloomsburg University's campus, Starbucks appeared most often as a conceptually salient landmark for students using mobile maps. While this study used a location-finding task, not a wayfinding task, it does align with the findings of Münzer et al. (2006) and Willis et al. (2009) on the significance of landmarks for mobile map users. Given the prominence of the Starbucks point of interest on the maps, this is also consistent with Fabrikant, Hespanha, and Hegarty's (2010) findings that, when presented with salient map features, map readers may ignore less conceptually salient, but still task-relevant information such as the spatial configuration of streets or building footprint outlines.

Employing an open-ended, situated approach focused on knowledge production allows us to highlight a new consideration: the potential impact of contextual social processes in making some features more conceptually salient than others. Many study participants used Starbucks as visual confirmation and one even specifically searched for it to locate the library. Furthermore, a large majority of research participants used a search function to locate the library, as opposed to panning and zooming. This indicates a reliance on the search function even when it is neither strictly necessary nor efficient. It also stands in contrast to the panning and zooming vision described by Kingsbury and Jones (2009) for Google Earth. In that formulation of Google Earth, the ability to move around the digital map virtually offers a playful, Dionysian contestation of the top-down, hegemonic vision implied by global mapping. Here, despite having this ability, users engaged with digital maps as banal tools for accomplishing a specific (prompted) task. Relying on search reinforces the power of algorithmic place-ranking (Zook and Graham 2007a) and technologically focuses on point-locations. This point-oriented geographic practice fits with and facilitates the landmark-orientation of participants' geographic knowledges, bypassing the surrounding spatial configurations that may be seen through panning and zooming across the map.

It is clear why Starbucks is conceptually salient for participants. It is a well-known entity on campus and a common meeting place, identifiable to and frequently visited by many in the community. However, Starbucks is not alone in these qualities. Several other sites, including other food franchises, the student services center, dining halls, and the student union also enjoy that status. There are even several comparable geographic features or meeting places next to or within the library, including the library lobby/ lounge, outdoor benches and tables, sculptures, a fountain, and the campus quad. What was different about Starbucks in this context was its prominence as a point of interest on both the Google Maps and Apple Maps mobile applications. 
At the time of this research, Starbucks was the only point of interest to consistently appear on the Google Maps application with both an icon and a label at the auto-zoom level of search results for "Bloomsburg University" and the library, aside from a placemark for the search results themselves (see Figure 1). Both the coffee icon and the Starbucks label also appeared when participants panned and zoomed to see the entirety of BU's lower campus. Other business and university landmarks appeared when users zoomed in further. Similarly, in the Apple Maps search results and panning/zooming, the other Starbucks franchise on the opposite end of lower campus (the location mistaken for the library by some participants) was the only location with a label and an icon, aside from a point of interest for the university as a whole. Zooming in on Apple Maps revealed only a redundant generic Bloomsburg University icon and additional businesses near campus. These features appeared across multiple research participants' devices, indicating a general design that was not presenting individually tailored points of interest, which both Google and Apple provide to users at times. Alternatively, Google and Apple may have been tailoring their maps to all focus group participants in the same way possibly because they were connecting via the university's network or companies identified them all as associated with Bloomsburg University.

\section{POINTS OF INTEREST AS LANDMARKS}

RESEARCh PARTICIPANTs' usE of Starbucks as a landmark point of reference cannot be entirely explained by traditional theorizations of landmark salience such as visual novelty, cultural or historical novelty, formal aesthetic quality, or geographic connectedness (Sorrows and Hirtle 1999; Raubal and Winter 2002). This Starbucks franchise is not visually notable in the landscape, lacking even exterior signage. Neither is it historically noteworthy nor culturally unique. Its location is on the back end of campus, near but not on several major campus paths. It is a frequent meeting place on campus, imparting it some cultural importance in the campus community, but it is only one of several such places, even in that immediate vicinity.

Starbucks' salience does fit neatly with the prominence of business-type features in web maps (Zook and Graham 2007a; 2007b; Dalton 2013). Due to the size of worldwide mobile map datasets, points of interest are selected for display through automated, algorithmic processes. Multiple studies have reported on the development of such processes, though without business-oriented considerations in the algorithms' design. Strategies include systematic rating of photographs for semantic characteristics; crowd-sourced volunteered geographic information; and scraped social media data, such as geolocated tweets and Foursquare check-ins (Binksi, Zhang, and Dalyot 2016; Quesnot and Roche 2015; Zhu and Karimi 2015). The extent to which Google or Apple employ similar methods is harder to know. These companies keep their algorithms for choosing points of interest as trade secrets, akin to the code that prioritizes search results. What outside researchers can know is, first, what companies say about how they design map services to serve their business strategies, and, second, the outputs that those map services provide.

\section{A GEOGRAPHIC BUSINESS STRATEGY}

As private companies, corporations like Google and Apple are driven to design technologies-including maps and geographic algorithms - that advance each company's business strategy, though that process is not as simple as prioritizing businesses that pay for ads. Instead, it reflects a broader strategy of collecting geographic data cheaply from a variety of sources and emphasizing features that potentially provide economic value. Google, for example, makes the lion's share of its revenue by collecting data from users and using that data to target advertisements to them. Google's and Apple's capital imperatives drive the collection of cheap, publicly available geographic datasets and the design of algorithms that pull information from those datasets. Crucially, however, showing businesses that might advertise with Google is only one part of Google's comprehensive business strategy. Broadly speaking, Google attempts to make as much information as possible searchable and usable online, including geographic data. Increasing the total amount of usable online information increases the amount of data that is commercially valuable for their targeted advertising business, as well as increasing the use-value of Google (or Apple) services for users (Battelle 2005; Gundotra 2008; Hillis, Petit, and Jarrett 2012). More useful data make for more successful uses of the company's services, providing consumers a good reason to use same services again and again, becoming a technological ritual practiced many times a 
day. At least some of these uses are commercially relevant, even if the initial use was not (Hillis, Petit, and Jarrett 2012). Moreover, on a technical level, businesses are easy, and therefore cheap, points of interest to include in map datasets, for they must have registered, point-based street addresses. Culturally significant locations, such as monuments or nature preserves, may not.

Given this general strategy, even if the Starbucks location on campus doesn't buy ad space, the map application as a whole is structured around data that bear street addresses, such as businesses and residences. Much like Google's internet search results and their associated ads, the map application and the points of interest it presents are structured around regular, everyday use and the presumption that at least some of those uses can be monetized with advertising, even if the search location hasn't been connected to an ad thus far.

\section{MAP SERVICE OUTPUTS}

While the specific mechanisms by which Google's and Apple's business strategies are implemented in code are secret, we can examine the outputs of those processes on public-facing map services in the form of search results, points of interest, and the maps themselves. Existing research demonstrates the centrality of businesses to Google Maps, particularly in the context of ranking algorithms, de facto urban racial segregation, third-party software developers, and geodemographic targeting (Zook and Graham 2007a; Crutcher and Zook 2009; Dalton 2015; Thatcher 2017).

This emphasis on businesses is also apparent in the points of interest symbolized and labeled on the maps of Bloomsburg University. At the time of research (early 2015), Starbucks was the most prominently marked point of interest on the Google Maps mobile app, but a user could also zoom in to see a label and icon for the Steak 'n Shake franchise, two snack bars serviced by Aramark, the library, the bookstore, the campus police office, two stadiums, a point of interest for the university as a whole, a mislocated Western Union franchise, and the private hospital next door. Apple Maps shows fewer points of interest, but in a similar vein. From the standpoint of someone finding their way around campus, there are hundreds of potential landmarks including dining halls, the student center, dorms, academic buildings, administrative buildings, the university's performing arts center, unique architectural features, monuments, sculptures, fountains, picnic areas, emergency phones, and-most significantly-the campus quad.

Another map-based mobile application, Pokémon Go, provides a useful counterpoint to what kinds of features can appear as points of interest on a mobile map. Unlike Google or Apple Maps, Pokémon Go is a location/mapbased game, which includes in-game features, "Pokéstops," at noteworthy, real-world locations. Initially, those locations were derived from databases of culturally significant sites and crowdsourcing. Locations tended to be post offices, monuments, churches, unusual architectural features, and even graffiti art. Unlike Google Maps, the game is not designed to facilitate finding and navigating to businesses. Relatively few businesses appear in the game and those that do are often well known and locally owned. At Bloomsburg University, this differing set of priorities is immediately apparent in the game, as most Pokéstops on campus are public art pieces. As of July 2016, almost none of the important sites in Pokémon Go appeared as discrete points of interest in Google Maps or Apple Maps. More recently, however, the game has begun to include "sponsored" location features, including Sprint Mobile stores and Starbucks (Perez 2016).

After we conducted our focus groups, Google announced that it would begin putting "promoted places" advertisements on its mobile device maps, including brand logos for Walgreens and Starbucks (Marvin 2016). Other, smaller geographic technology companies that provide business reviews and ratings, such as Foursquare and Yelp!, have long employed such cartographic advertising strategies. Similarly, location-based ads are common in non-cartographic applications including other Google services, Facebook, Snapchat, Lyft and many other mobile device applications, because location is thought to be a very strong predictor of a user's consumer preferences (Swift 2011). Until recently, ads within the map view itself were uncommon in general-purpose web maps from Google and Apple. In practice, these changes mean that advertisements will appear in Google Maps at the location of that business, even if they are irrelevant to the user's search terms. For example, if someone were to search for "Bloomsburg Park," the Starbucks logo and/or name would still appear on the map.

In addition to placing ads directly on maps, in 2018 Google began to test incorporating points of interest as 


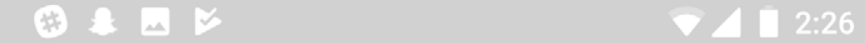

$2 \mathrm{~d} 11 \mathrm{hr}(4,298 \mathrm{~km})$

$\uparrow \quad$ Continue straight onto W Emory Rd

$400 \mathrm{~m}$

$\uparrow \quad$ Continue straight onto Karns Valley Dr

$1.6 \mathrm{~km}$

Turn right onto TN-62 W

(i) Pass by Waffle House (on the left in 12.6 km)

$40 \mathrm{~km}$

4. Continue straight onto US-27 S

i) Pass by Ruby Tuesday (on the right in $10.4 \mathrm{~km}$ )

$24 \mathrm{~km}$

r Turn right onto US-70 W

$21 \mathrm{~km}$

7 Turn left onto Cox Valley Rd

$5.5 \mathrm{~km}$

r Turn right onto TN-68 N

69 SHOW MAP

\ PREVIEW
(4) 3 A

2 d 11 hr $(4,298$ km)

Merge onto Sgt Prentiss Dr

$\hat{\Lambda}$

(i) Pass by Advance Auto Parts (on the left in

$3.5 \mathrm{~km}$

Turn right onto US-425 N/US-84 W/John R Junkin Dr

$\rightarrow$ i Continue to follow US-425 N/US-84 W

(i) Pass by AutoZone (on the right in $20.2 \mathrm{~km}$ )

(i) Entering Louisiana

$21 \mathrm{~km}$

Turn left onto US-84 W/Louisiana Ave

4 (i) Continue to follow US-84 W

Pass by Dollar General (on the left in $28.1 \mathrm{~km}$ )

$44 \mathrm{~km}$

4 Turn left onto LA-28 W

(i) Pass by Dollar General (on the right in $32.4 \mathrm{~km}$ )

$39 \mathrm{~km}$

G) SHOW MAP

\ PREVIEW

Figures 3 \& 4. Business locations used as landmarks in Google Maps directions.

points of reference in its turn-by-turn directions. Such landmarks appear both as waypoints along a route and turning points in both the written and audio directions in the United States. If someone were following Google Maps' turn-by-turn directions, the map application might say "turn right at the McDonald's" instead of "in a quarter-mile, turn right." Of those points of interest that we observed or that have been reported as being used as landmarks in turn-by-turn directions, all have been chain businesses, including: Bank of America, AutoZone, Pet Valu, Rite Aid, Liberty Tax Service, Dollar General, Sleep Inn \& Suites, Chipotle, McDonald's, Pizza Hut, and, inevitably, Starbucks (Ihnat 2018; Dickey 2018).
Through map services designed to serve Google's and Apple's business plans, the Starbucks in the Bloomsburg University library became a cartographically prominent point of interest. For many research participants, that prominent point of interest served as a landmark, connecting the map to their experience, confirming their understanding of the area and allowing them to find the library. As points of interest become used as landmarks, they may shape users' ways of seeing, producing geographic knowledges that are functional, but that are also shaped by the business plans behind the maps they use. Starbucks may have been a noteworthy place for students before they looked at the map. Once they use the map, 
however, it becomes a landmark point of reference with which to connect their experience, particularly due to the limited number of other features that appear. Participants' geographic knowledges "are not stable entities, but are dynamic: constantly changing and evolving” (Kitchin 1994,
6; Webber, Symanski, and Root 1976). Research participants' use of and repeated spoken references to Starbucks both indicate that their knowledges are being (re)produced in the map's terms, in part reflecting the business priorities of the mapmaker.

\section{CONCLUSIONS}

IT IS SAFE TO ASSUME that branded businesses have long served as landmarks in both locating places and wayfinding practice. The role of such locations as landmarks on mobile maps constitutes something deeper. Starbucks appears alone on the map, which has the effect of reifying and strengthening Starbucks-branded locations as landmarks. Given the hundreds of millions of mobile map users, these sorts of landmarks and the social conditions that created them are now part of the production of everyday geographic knowledges.

Social context matters in analyses of map use and geographic knowledge. Political economic processes are influential, defining the purpose for most mobile maps and leading developers to design maps that function in some ways and not others, that prioritize certain kinds of features at the expense of others. Down the line, that purposeful design limits a user's point-of-reference options when reading the map. In this case, the business imperative underlying the design of the Google Maps and Apple Maps applications prioritizes business points of interest. In practice, as users connect their personal experience with the map, potential landmarks are thus likely to be businesses, shaping how their geographic knowledges are produced and, potentially, their actions.

Cognitive and cultural geographic approaches that conceptualize geographic knowledges as contextual have a great deal to offer research on mobile device use. Without approaching mobile map users and their knowledges as situated amidst powerful, ongoing social processes, we would have overlooked the role of companies in shaping the design of mobile maps and not seen the importance of Starbucks as a landmark among research participants. Taking a situated approach to understanding the geographic uses of mobile devices offers new insights and opens navigational questions as a productive field for data scholarship.
On a societal level, it seems likely that the prevalence of businesses as landmarks will become more common. Mobile phones and maps are already key data sources in smart city projects (Kitchin 2014), which poses questions about privacy and the commodification not only of data, but also people's individual movements. As Google's preliminary use of point of interest landmarks makes clear, companies are increasingly focused on providing turn-byturn directions based on landmarks (Duckham, Winter, and Robinson 2010; Ihnat 2018; Dickey 2018). The next logical step is placing location-based ads within directions. Much like ads on the map, businesses could pay to place an advertisement within your directions whenever you happen to be driving by a franchise.

Given the focus of mobile map users on landmarks, these directions might facilitate more effective wayfinding. Nevertheless, such a system would also facilitate advertising branding strategies that bank on repeated encounters with a name or logo, even if there were no explicit sales pitch. It could also cause navigational problems when a business closes, disappearing from the landscape but persisting in the turn-by-turn directions. Finally, it raises issues involving the uneven nature of markets and subsequent mapping. Would such maps favor chain businesses over local shops (Zook and Graham 2007a)? Will such geographic knowledges perpetuate the digital divide in poorer neighborhoods and poorer countries? Areas with less data and fewer businesses might be harder to navigate. Some might be avoided altogether as in Microsoft's notorious "avoid the ghetto" application (Thatcher 2013). Whatever the outcomes, analyzing the production of geographic knowledges through mobile technologies will be important to knowing how we see and understand the world around us. 
Thank you, Karen Wilwol, for assisting in the focus groups and with the transcription. Thank you to Amy Griffin, Daniel Huffman, and the anonymous reviewers for their guidance in getting this article to print.

\section{REFERENCES}

Alvarez León, Luis F., and Colin J. Gleason. 2017. "Production, Property, and the Construction of Remote Sensing Data." Annals of the American Association of Geographers 107 (5): 1-15. doi: 10.1080/24694452.2017.1293498.

Anderson, Monica. 2016. "More Americans Using Smartphones for Getting Directions, Streaming TV.” Pew Research Center FactTank. January 29, 2016. http://www.pewresearch.org/fact-tank/2016/01/29/ us-smartphone-use.

Axon, Stephen, Janet Speake, and Kevin Crawford. 2012. “'At the Next Junction, Turn Left': Attitudes Towards Sat Nav Use.” Area 44 (2): 170-177. doi: 10.1111/j.1475-4762.2012.01086.x.

Bartie, Phil, William Mackaness, Philipp Petrenz, and Anna Dickinson. 2015. "Identifying Related Landmark Tags in Urban Scenes Using Spatial and Semantic Clustering." Computers, Environment and Urban Systems 52: 48-57. doi: 10.1016/j. compenvurbsys.2015.03.003.

Basiri, Anahid, Pouria Amirian, Adam Winstanley, Stuart Marsch, Terry Moore, and Guillaume Gales. 2016. "Seamless Pedestrian Positioning and Navigation Using Landmarks.” Journal of Navigation 69 (1): 24-40. doi: 10.1017/S0373463315000442.

Battelle, John. 2005. The Search: How Google and Its Rivals Rewrote the Rules of Business and Transformed Our Culture. New York: Penguin Group.

Binksi, N., L. Zhang, and Sagi Dalyot. 2016. "Wikipedia Entries as a Source of Car Navigation Landmarks." ISPRS Annals of the Photogrammetry, Remote Sensing and Spatial Information Science 3 (2): 45-52.
Brown, Barry, and Eric Laurier. 2005. "Maps and Journeys: An Ethno-Methodological Investigation." Cartographica 40 (3): 17-33. doi: 10.3138/6QPX-0V10-24R0-0621.

Cosgrove, Denis. 1998. Social Formation and Symbolic Landscape, 2nd Edition. Madison, WI: University of Wisconsin Press.

Crampton, Jeremy. 2010. Mapping: A Critical Introduction to Cartography and GIS. Chichester, UK: John Wiley and Sons.

Crutcher, Michael, and Matthew Zook. 2009. "Placemarks and Waterlines: Racialized Cyberscapes in Post Katrina Google Earth.” GeoForum 40 (4): 523-534. doi: 10.1016/j.geoforum.2009.01.003.

Darlington, Shasta. 2015. "Waze App Directions Take Woman to Wrong Brazil Address, Where She Is Killed." CNN, October 8, 2015. http://www.cnn.com/2015/10/05/americas/ brazil-wrong-directions-death.

Dalton, Craig. 2013. "Sovereigns, Spooks, and Hackers: An Early History of Google Geo Services and Map Mashups." Cartographica 48 (4): 261-274. doi: 10.3138/ carto.48.4.1621.

2015. "For Fun and Profit: the Limits and Possibilities of Google-Maps-Based Geoweb Applications" Environment and Planning A 47 (5): 1029-1046. doi: 10.1177/0308518X15592302.

- 2018. "Big Data From the Ground Up: Mobile Maps and Geographic Knowledges.” The Professional Geographer 70 (1): 157-164. doi: 10.1080/00330124.2017.1326085. 
Dickey, Megan Rose. 2018. "Google Maps to Drivers: Turn Right at the Burger King." TechCrunch, April 18, 2018. https://techcrunch.com/2018/04/18/googlemaps-to-drivers-turn-right-at-the-burger-king.

Dodge, Martin, and Rob Kitchin. 2007. "Rethinking Maps.” Progress in Human Geography 31 (3): 331-344. doi: 10.1177/0309132507077082.

Duckham, Matt, Stephan Winter, and Michelle Robinson. 2010. "Including Landmarks in Routing Instructions." Journal of Location Based Services 4 (1): 28-52. doi: 10.1080/17489721003785602.

Fabrikant, Sara Irina, Stacy Rebich Hespanha, and Mary Hegarty. 2010. "Cognitively Inspired and Preceptually Salient Graphic Displays for Efficient Spatial Inference Making." Annals of the Association of American Geographers 100 (1): 13-29. doi: 10.1080/00045600903362378.

Feenberg, Andrew. 1999. Questioning Technology. New York: Routledge.

Field, Kenneth, James O'Brien, and Linda Beale. 2011. "Paper Maps or GPS? Exploring Differences in Wayfinding Behavior and Spatial Knowledge Acquisition.” Paper presented at the 25th International Cartographic Conference, Paris, France, July 3-8, 2011. http://icaci.org/files/documents/ICC_ proceedings/ICC2011/Oral\%20Presentations\%20 PDF/C2-Mapping\%20network\%20and\%20route/ CO-229.pdf.

Freundschuh, Scott M., and Max J. Egenhofer. 1997. "Human Conceptions of Spaces: Implications for Geographic Information Systems." Transactions in GIS 2 (4): 361-375. doi: 10.1111/j.1467-9671.1997. tb00063.x.

Graham, Mark. 2015. “The Hidden Biases of Geodata.” The Guardian, April 30, 2015. http://www. theguardian.com/news/datablog/2015/apr/28/ the-hidden-biases-of-geodata.

Graham, Stephen. 2005. "Software-Sorted Geographies." Progress in Human Geography 29 (5): 562-580. doi: 10.1191/0309132505ph568oa.
Griffin, Amy L. 2017. "Cartography, Visual Perception, and Cognitive Psychology.” In The Routledge Handbook of Mapping and Cartography, edited by Alexander J. Kent and Peter Vujakovic, 44-54. New York: Routledge.

Gundotra, Victor. 2008. "Client, Connectivity and the Cloud.” Keynote at Google I/O 2008, San Francisco, CA, May 28th, 2008.

Haklay, Mordechai. 2013. "Neogeography and the Delusion of Democratisation." Environment and Planning A 45 (1): 55-69. doi: 10.1068/a45184.

Hamburger, Kai, and Florian Röser. 2014 “The Role of Landmark Modality and Familiarity in Human Wayfinding." Swiss Journal of Psychology 73 (4): 205-213.

Haraway, Donna. 1991. Simians, Cyborgs, and Women: The Reinvention of Nature. New York: Routledge.

Held, Richard, and Alan Hein. 1963. "MovementProduced Stimulation in the Development of Visually Guided Behaviour." Journal of Comparative and Physiological Psychology 56 (5): 872-876. doi: 10.1037/ h0040546.

Hillis, Ken, Michael Petit, and Kylie Jarrett. 2012. Google and the Culture of Search. New York: Routledge.

Huang, Haosheng, Manuela Schmidt, and Georg Gartner. 2012. "Spatial Knowledge Acquisition with Mobile Maps, Augmented Reality and Voice in the Context of GPS-Based Pedestrian Navigation: Results from a Field Test." Cartography and Geographic Information Science 39 (2): 107-116. doi: 10.1559/15230406392107.

Ihnat, Gwen. 2018. “Google Maps May Tell You, 'Turn Left at the McDonald's." The Takeout, April 17th, 2018. https://thetakeout.com/google-maps-may-nowtell-you-turn-left-at-mcdonald-s-1825323023.

Ishikawa, Toru, Hiromichi Fujiwara, Osamu Imai, Atsuyuki Okab. 2008. "Wayfinding with a GPSBased Mobile Navigation System: A Comparison with Maps and Direct Experience." Journal of Environmental Psychology 28: 74-82. doi: 10.1016/j. jenvp.2007.09.002. 
Kingsbury, Paul, and John Paul Jones. 2009. "Walter

Benjamin's Dionysian Adventures on Google

Earth." Geoforum 40: 502-513. doi: 10.1016/j.

geoforum.2008.10.002.

Kitchin, Rob. 1994. "Cognitive Maps: What are They and Why Study Them?" Journal of Environmental Psychology 14: 1-19. doi: 10.1016/S0272-4944(05)80194-X.

2014. "The Real-Time City? Big Data and Smart

Urbanism.” GeoJournal 79 (1): 1-14. doi: 10.1007/ s10708-013-9516-8.

Lynch, Kevin. 1960. The Image of the City. Cambridge, MA: MIT Press.

MacEachren, Alan. 1995. How Maps Work. New York: Guilford.

Marvin, Ginny. 2016. "Retailers Testing Google Maps Mobile Promoted Places Ads Include MAC Cosmetics, Starbucks, Walgreens.” Search Engine Land, Dec. 15, 2016. http://searchengineland.com/ promoted-pins-google-maps-beta-265559.

McBride, Sarah, and Alexi Oreskovic. 2013. "Google Eyes Waze as Facebook Circles Hot Web Maps Property." Reuters, May 24, 2013. http://www. reuters.com/article/2013/05/24/us-waze-googleidUSBRE94N02H20130524 ?irpc=932.

Milner, Greg. 2016. “Death by GPS.” ArsTechnica, May 3, 2016. http://arstechnica.com/cars/2016/05/ death-by-gps.

Monmonier, Mark, and Myke Gluck. 1994.

"Focus Groups for Design Improvement in Dynamic Cartography." Cartography and Geographic Information Systems 21 (1): 37-47. doi: 10.1559/152304094782563948.

Montello, Daniel R. 2009. "Cognitive Research in GIScience: Recent Achievements and Future Prospects." Geography Compass 3 (5): 1824-1840. doi: 10.1111/j.1749-8198.2009.00273.x.
Montello, Daniel R., and Scott Freundschuh. 2005. "Cognition of Geographic Information." In $A$ Research Agenda for Geographic Information Science, edited by Robert B. McMaster and E. Lynn Usery, 61-91. Boca Raton, FL: CRC Press.

Moore, Gary, and Reginald Golledge. 1976.

"Environmental Knowing: Concepts and Theories." In Environmental Knowing, edited by Gary T. Moore and Reginald G. Golledge, 138-164. Stroudsburg, PA: Dowden Hutchinson \& Ross.

Münzer, Stefan, Hubert D. Zimmer, Maximilian Schwalm, Jörg Baus, and Ilhan Aslan. 2006. "Computer-Assisted Navigation and the Acquisition of Route and Survey Knowledge." Journal of Environmental Psychology 26: 300-308. doi: 10.1016/j. jenvp.2006.08.001.

Münzer, Stefan, Hubert D. Zimmer, and Jörg Baus. 2012. "Navigation Assistance: A Trade-off Between Wayfinding Support and Configural Learning Support." Journal of Experimental Psychology: Applied, 18 (1): 18-37. doi: 10.1037/a0026553.

Parush, Avi, Shir Ahuvia-Pick, and Ido Erev. 2007. "Degradation in Spatial Knowledge Acquisition When Using Automatic Navigation Systems.” In Spatial Information Theory, edited by Stephan Winter, Matt Duckham, Lars Kulik, and Ben Kuipers, 238-254. Berlin: Springer. doi: 10.1007/978-3-540-74788-8_15.

Perez, Sarah. 2016. "Mario Arrives as Pokemon Go Peaks, with Declining Downloads, Falling Revenue." TechCrunch, December 15, 2016. https://techcrunch. com/2016/12/15/mario-arrives-as-pokemon-gopeaks-with-declining-downloads-falling-revenue.

Pickles, John. 2004. A History of Spaces. New York: Routledge.

Pink, Sarah, and Larissa Hjorth. 2012. "Emplaced Cartographies: Reconceptualising Camera Phone Practices in an Age of Locative Media." Media International Australia 145 (1): 145-155. doi: 10.1177/1329878X1214500116. 
Poushter, Jacob. 2016. "Smartphone Ownership and Internet Usage Continues to Climb in Emerging Economies." Perw Research Center Global Attitudes E Trends, February 22, 2016. http://www.pewglobal. org/2016/02/22/smartphone-ownership-and-internetusage-continues-to-climb-in-emerging-economies.

Quesnot, Teriitutea, and Stéphane Roche. 2015. "Measure of Landmark Semantic Salience Through Geosocial Data Streams." ISPRS International Journal of Geo-information 4: 1-31. doi: 10.3390/ijgi4010001.

Raubal, Martin, and Stephan Winter. 2002. "Enriching Wayfinding Instructions with Local Landmarks." In Geographic Information Science, edited by Max J. Egenhofer and David M. Mark, 243-259. Berlin: Springer. doi: 10.1007/3-540-45799-2_17.

Ricker, Britta, Nadine Schuurman, and Fritz Kessler. 2015. "Implications of Smartphone Usage on Privacy and Spatial Cognition: Academic Literature and Public Perceptions." GeoJournal 80 (5): 637-652. doi: 10.1007/ s10708-014-9568-4.

Rose, Gillian. 2003. "On The Need to Ask How, Exactly, Is Geography 'Visual'?” Antipode 35 (2): 212-221. doi: 10.1111/1467-8330.00317.

2007. Visual Methodologies, an Introduction to the Interpretation of Visual Materials, 2nd Edition. Thousand Oaks, CA: SAGE Publications.

Royal Institute of Navigation. 2015. "Society 'Sedated by Software' Needs Nav Skills Taught at School.” Press release. May 1 2015. Accessed September 24, 2016. https://web.archive.org/web/20150507002436/http:// www.rin.org.uk/newsitem/4060/Society-.

Schulten, Susan. 2012. Mapping the Nation: History and Cartography in Nineteenth-Century America. Chicago: University of Chicago Press.

Shelton, Taylor, Matt Zook, and Alan Wiig. 2015. "The 'Actually Existing Smart City." Cambridge Journal of Regions, Economy, and Society 8 (1): 13-25. doi: 10.1093/cjres/rsu026.
Sorrows, Molly E., and Stephen C. Hirtle. 1999.

"The Nature of Landmarks for Real and Electronic Spaces." In Spatial Information Theory. Cognitive and Computational Foundations of Geographic Information Science, edited by Christian Freksa and David M. Mark, 37-50. Berlin: Springer. doi: 10.1007/3-540-48384-5_3.

Speake, Janet. 2015. “I've Got My Sat Nav, It's Alright': Users' Attitudes Towards, and Engagements with, Technologies of Navigation." The Cartographic Journal 52 (4): 345-355. doi: 10.1080/00087041.2015.1108663.

Stephens, Monica. 2013. “Gender and the Geoweb: Divisions in the Production of User-Generated Cartographic Information.” GeoJournal 78 (6): 981996. doi: 10.1007/s10708-013-9492-z.

Sutton, Elizabeth A. 2015. Capitalism and Cartography in the Dutch Golden Age. Chicago: University of Chicago Press.

Swift, Mike. 2011. "Google Emails Highlight Value of Location Data." San Jose Mercury Nerws, April 30, 2011. https://www.mercurynews.com/2011/04/29/ google-emails-highlight-value-of-location-data.

Sutko Daniel M., and Adriana de Souza e Silva. 2011. "Location-Aware Mobile Media and Urban Sustainability." New Media Society 13: 807-823. doi: 10.1177/1461444810385202.

Taylor, Linnet. 2015. "Inside the Black Box of Internet Adoption: The Role of Migration and Networking in Internet Penetration in West Africa." Policy E Internet 7 (4): 423-446. doi: 10.1002/poi3.87.

Thatcher, Jim. 2013. "Avoiding the Ghetto Through Hope and Fear: An Analysis of Immanent Technology Using Ideal Types." GeoJournal 78 (6): 967-980. doi: 10.1007/ s10708-013-9491-0.

_. 2017. "You Are Where You Go, the Commodification of Daily Life Through 'Location'." Environment and Planning A 49 (12): 2702-2717. doi: 10.1177/0308518X17730580. 
Thatcher, Jim, David O'Sullivan, and Dillon Mahmoudi. 2016. "Data Colonialism Through Accumulation by Dispossession: New Metaphors for Daily Data." Environment and Planning D: Society and Space 34 (6): 990-1006. doi: 10.1177/0263775816633195.

Tversky, Barbara. 1993. "Cognitive Maps, Cognitive Collages, and Spatial Mental Models." In Spatial Information Theory: A Theoretical Basis for GIS, Proceedings COSIT '93, edited by Andrew U. Frank and Irene Campari, 14-24. Berlin: Springer. doi: 10.1007/3-540-57207-4.

Wang, Dan, Sangwon Park, and Daniel R. Fesenmaier. 2012. "The Role of Smartphones in Mediating the Touristic Experience." Journal of Travel Research 51 (4): 371-387. doi: 10.1177/0047287511426341.

Waters, Wilfred, and Stephan Winter. 2011. "A Wayfinding Aid to Increase Navigator Independence.” Journal of Spatial Information Science 3: 103-122.

Webber, M. J., Richard Symanski, and James Root. 1975. "Toward a Cognitive Spatial Theory." Economic Geography 51 (2): 100-116.

Willis, Katherine S. 2016. Netspaces: Space and Place in a Networked World. New York: Ashgate.

Willis, Katherine S., Christoph Hoelscher, Gregor Wilbertz, and Chao Li. 2009. "A Comparison of Spatial Knowledge Acquisition with Maps and Mobile Maps." Computers Environment and Urban Systems 33: 100-110. doi: 10.1016/j.compenvurbsys.2009.01.004.
Wilmott, Clancy. 2016. "Small Moments in Spatial Big Data: Calculability, Authority and Interoperability in Everyday Mobile Mapping." Big Data and Society 3(2): 1-16. doi: doi.org/10.1177/2053951716661364.

Wilson, Matthew W. 2011. “Training the Eye':

Formation of the Geocoding Subject." Social E' Cultural Geography 12 (4): 357-376. doi: 10.1080/14649365.2010.521856.

2012. "Location Based Services, Conspicuous Mobility, and the Location-Aware Future." Geoforum 43 (6): 1266-1275. doi: 10.1016/j. geoforum.2012.03.014.

Zhu, Rui, and Hassan A. Karimi. 2015. "Automatic Selection of Landmarks for Navigation Guidance.” Transactions in GIS 19 (2): 247-261. doi: 10.1111/ tgis.12095.

Zook, Matt, and Mark Graham. 2007a. "The Creative Reconstruction of the Internet: Google and the Privatization of Cyberspace and DigiPlace.” Geoforum 38 (6): 1322-1343. doi: 10.1016/j. geoforum.2007.05.004.

2007b. "Mapping DigiPlace: Geocoded Internet Data and the Representation of Place." Environment and Planning B: Planning and Design 34: 466-482. doi: 10.1068/b3311. 